\title{
INFORMATION AND COMMUNICATION TECHNOLOGIES AS THE MANAGEMENT FACTOR IN THE DIGITAL ECONOMY DEVELOPMENT
}

\author{
Igor Sergeev ${ }^{1}$ \\ Kristina Kukushkina ${ }^{2}$
}

https://doi.org/10.31410/itema.2018.1

\begin{abstract}
The article is focused on the analysis of the information and communication technologies use in economic activity. Every day global economic relations experience fundamental changes. It becomes more difficult to identify even the simplest connections between phenomena and objects. New economy transition implies that digital technologies and services become the key factors of this activity. Economic relations' transition into digital reality, based on the digitized data movement through communication channels of information networks, has become objective and inevitable. The methodology: description, analysis, synthesis, generalization, formalization, structural and functional approach, justification, modelling. Conclusions: Firstly, since digital reality is a system, the basic concept of digitalization is a digital platform, which is an information and communication environment, where all the necessary hardware and software, including a complex of services, are concentrated. Secondly, formation of digital platforms is a consequence of the digital transformation [1]. This process is associated with the development of a new economic management model. Currently, market relations naturally rush from program-target to program-forecast. Prime examples of platform solutions implementation are online platforms such as Uber and Airbnb. Thirdly, since all platforms are based on information and communication technologies, the communication is carried out instantly and in a simplified manner. Digital platform is a natural evolutionary directed modification of business structures. As a general rule, the government does not stimulate business development of platform solutions. However, it should be borne in mind that the political will must simultaneously encourage and simplify the digital platforms formation in business environment [2]. Fourthly, an analysis of the digital platform concept suggests that it is an important source of open data that are relevant to state economic policy building. In addition, thanks to digital platforms, there are opportunities for analytics, forecasting and the creation of multifunctional services in the field of economic relations management. Theoretical and practical significance: This study clarifies the methodology for the information and communication technologies development in economic activity, allows to estimate the subjects' collaboration as well as the digital platforms' formation in the digital transformation of the economy.
\end{abstract}

Keywords: economic activity, digital economy, digital platform, information and communication technologies, software, information networks.

\footnotetext{
${ }^{1}$ Russian Customs Academy, Komsomolsky av. 4. Lyubertsy, Russia

${ }^{2}$ Russian Customs Academy, Komsomolsky av. 4. Lyubertsy, Russia
} 


\section{INTRODUCTION}

$\mathrm{C}$

urrently, the world community has entered into the stage of global change. All the spheres of life - the economy, science, education and security acquire new content that will be available to humanity in radically different forms. The reason for these changes was the introduction of digital technologies, and the phenomenon of the transition of most significant processes into the digital reality, based on the digitized data movement through the information technology communication channel.

The economy digitization is becoming the key element of modern life, filling its various niches, manifesting previously unknown prospects for the "non-biological mind" formation with its superiority over the human brain functionality and creativity, free from the human limitations.

Continuously the communication technologies shrink the space and time, change the labor exploiting and capital accumulating practices, as well as the very nature of the reproduction processes.

\section{DIGITAL ECONOMY AS A CONSEQUENCE OF INFORMATION AND COMMUNICATION TECHNOLOGIES DEVELOPMENT}

Experts note that the digital economy creation is the necessity associated with the progress in such areas as microelectronics, information technology and telecommunications, digital currency instruments and other components of the term "digital economy" [3].

This concept, applied in 1995 at the University of Massachusetts by the American scientist Nicholas Negroponte [4], was generated by the intensive development of information and communication technologies. Operations in the field of the Internet and mobile communications were developed first of all, so they can be called "the basic technologies of the digital economy". However, as a result of expanding the information and communication technologies' capabilities, these processes have become the basis and predetermined the development vector of such industries as manufacturing, healthcare, education, financial services, and transport.

The peculiarity of the economy of the new order is represented by the digital, voluminous and multi-sectoral data, while the advantage of accelerated economic development are those countries whose economies are based on the most advanced electronic technologies and services, including "big data" analysis technologies and forecasting technologies. Even though, despite of the accelerated regulatory and legal consolidation of such concepts as the digital economy, information and communication technologies, end-to-end technologies, digitalization, still remain blurred and are interpreted differently [5].

Foreign countries can be divided into 4 groups in the terms of digitalization:

- In the first group are the United Kingdom, Japan, Singapore, Hong Kong. All these countries show the highest level of digital development and rapid growth rates;

- In the second group are Australia, South Korea, Western European countries and Scandinavia. These countries have maintained rapid growth, but they are now reducing the level of investment;

- In the third group are Russia, India, China can potentially become leading;

- The fourth group constitute the countries of Africa and South America. They are characterized by the development low level. 
The content of the world relations is undergoing cardinal changes daily. It becomes more difficult to identify even the simplest connections between phenomena and objects. Modern economic conditions require the formation and development of the world economy as a hightech and innovative system in order to ensure the meaningful growth rate and the competitiveness of products in domestic and foreign markets.

The simple proof of the above are the similarities and differences of the real person and his image in the Internet space. The more information is stored in such a device as the smartphone the less work is done by the person. The integration of virtual processes in real life leads to the creation of a new hybrid world. This world is a system where the satisfaction of the basic needs of the real world is possible only through the use of information and communication technologies and digital infrastructure. In the other words, all operations related to household requests require the inclusion of digital applications. Consequently, more complex social relations will soon be based primarily on information and communication technologies.

At the moment, there is no consensus on what the digital economy is and what role modern information and communication technologies play in its administration. In the Russian Federation, the definition is approved by the Presidential decree of May 9, 2017 No. 203 "On the Strategy for the Information Society Development in the Russian Federation for 2017$2030 "[6]$.

Digital economy refers to economic activity, where the key production factor is the digital data, processing large amounts of data and using analysis results which, compared to the traditional forms of management, can significantly improve the efficiency of various types of production, technologies, equipment, storage, sales, goods delivery and services.

This concept proves that the digital economy is one of the hybrid world subsystems. In other words, the digital economy is a management system. The main feature of this system is the impossibility of meeting the commercial and non-commercial needs of society without hightech analysis and information use. Systems for the information use are communication technologies, which are based primarily on financial infrastructures and digital government platforms.

\section{DIGITAL PLATFORMS ARE THE ECONOMY TRANSFORMATION TOOLS}

The basic concept of digitalization is the definition of the digital platform, which is information and communication environment that includes all the hardware and software necessary to meet public needs, including the complex of services. That is, the digital platform is a platform for the modern information concentration and communication technologies, which are intermediaries between the needs of individuals and legal entities. This platform is designed to support automated processes and accelerated consumption of digital services.

The digital platform in the broad sense is a system that allows legal entities, individuals and the state to manage partnerships, to enter transactions, provide services and interact with each other in any other way without intermediaries, using cognitive technologies.

The digital platforms formation is a consequence of the economy digital transformation. This process is associated with the new economic management model development. Currently, market relations naturally rush from the program-target to the program-forecast. This hybrid 
type of economy is mainly based on such a phenomena as electronic transaction and electronic commerce.

E-commerce, like classical commerce, requires the creation of specialized virtual and real platforms, which can be called digital platforms. The functional significance of the digital platform lies in the fact that it makes the integrated and effective information and communication technologies use possible. In addition, the digital platform provides the possibility of simplified and accelerated communication between the individuals and legal entities, which reduces the cost of finding interaction opportunities.

The success of the economy digital platforms is due to the interaction acceleration between traders and other participants, as well as due to the effectiveness of public administration within the platform. The digital platform as a model of subject interaction was implemented before this definition has appeared.

Prime examples of the platform solutions implementation are the online platforms such as Uber and Airbnb. These business projects were successful due to the fact that the trends of the Industry 4.0 were taken into account in their development. The term "Industry 4.0" appeared in Europe in 2011, when the German government has indicated the need for a wide application of information technologies in production [3].

Thus, the digital platform is a consequence and the necessary element of the fourth industrial revolution, which allows the individuals, legal entities and government bodies to use them in everyday life, in commercial and non-commercial activities of such innovations as the cognitive technologies, cloud solutions, Internet of things, big data, block-chains and cryptocurrencies. The digital high technology based platform creates profits through the exchange between the two or more independent groups of participants [4].

It is reasonable to say that the platforms provide the direct interaction between the manufacturers and the end users. In addition, digital platforms provide an opportunity to share projects and thus significantly increase the cooperation efficiency and to create innovative products and solutions. Platform companies are digital platforms in the narrow sense. [5].

Since all the platforms are based on information and communication technologies, the communication of participants is carried out instantly and in a simplified manner. In the other words, the digital platform performs the role of the operator that facilitates transactions immediately after a request.

The technologies that emerged in 2017 and 2018 are primarily based on cloud priorities, since at the moment this is the only way to process and analyze big data. Another important platform for the platform business is the product service format and flexible payment format. These features allow to increase the rate of new opportunities introduction in the markets. In addition to commercial platforms, there are state-owned digital platforms, which are the combination of government bodies and non-profit organizations that have introduced information and communication technologies into their community management process. 


\section{CONCLUSION}

As a rule, there are experimental models of the local digital platforms that correspond to these characteristics, but the technology development should lead to a single digital space where each subject can satisfy any need. Each of the participants in this space will be an element of the global digital ecosystem. In the formation of digital platforms, it is important that the conditions for their implementation meet the requirements of the information and communication technologies functioning [6].

\section{REFERENCES}

[1] Keshelava A.V., Budanov V.G., Rumyantsev V.U. Introduction to the Digital Economy // "On the threshold of the digital future." Book One, 2018. - $28 \mathrm{c}$.

[2] Gartner Research [Electronic resource] // URL: https://www.gartner.com/en

[3] Blockchain: level and development prospects: [Electronic resource]// BIT-новости. URL: https://bitnovosti.com/2017/03/18/blockchain-state-of-the-art-and-prospective/commentpage-1/.

[4] Presidential decree of May 9, 2017 No. 203 "On the Strategy for the Information Society Development in the Russian Federation for 2017-2030"

[5] Scientific and technical background of the "Digital Economy" [Electronic resource] // URL: https://data-economy.ru/science

[6] Financial results of platform projects [Electronic resource] // URL: https://ru.investing.com 